\title{
Numerical Study on Temperature Variation in Adsorption Bed under Solar Insolation
}

\author{
Dongdong Gao, Zhongxian Yuan* \\ College of Environmental and Energy Engineering, Beijing University of Technology, China
}

Copyright (C) 2015 by authors, all rights reserved. Authors agree that this article remains permanently open access under the terms of the Creative Commons Attribution License 4.0 International License

\begin{abstract}
The internal temperature change of an adsorbent bed, which is subjected to the solar insolation, has been numerically simulated. As the intensity of the solar radiation changes with the sun movement, the temperature distribution in the bed evolves continually. Based on the configuration of the evacuated tube bed, a two-dimensional model of heat transfer has been established and numerically solved. To identify the effect of the internal cooling mode, three kinds of thermal boundary condition have been applied to the cooling tunnel. The numerical results reveal that the uniform wall temperature condition presents the best cooling effect, while the natural air convection presents the worst effect. In addition, the temperature change of the bed with the bed diameter has been examined, incorporating with the effect of cooling channel size. For the cooling condition of the natural air convection, the sun-facing side of the bed not only warms up the most rapidly, but also shows the highest temperature. In contrast, the temperature rising of the sun-shading side is much less. The temperature difference between the sun-facing side and the sun-shading side can reach $70^{\circ} \mathrm{C}$. The non-uniform distribution of the temperature of the bed will hinder the adsorption cooling performance.
\end{abstract}

Keyword Solar Radiation, Adsorption Bed, Cooling Mode, Temperature

\section{Introduction}

Due to the solar energy is clean and renewable, and also due to the serious problems that have been resulted from the excessive exploitation of the fossil fuels such as the coal and the oil, the human society nowadays confronts the difficulty of the sustainable development. Correspondingly, efficient technologies of solar and the other renewable energies attract more and more researchers' attention. These advantages highly conform to the development trend of the environment and energy ${ }^{[1]}$. As a kind of green refrigeration technology, adsorption cooling has become a hot topic in recent years due to its advantages of low-grade driving heat source, no pollution and little noise etc. Especially, the adsorption refrigeration system driven by the solar energy is the most attractive mode. On the other hand, there are still many technical difficulties that frustrate the wide application of the solar adsorption cooling. In addition to the problem of low adsorption rate of the adsorbent material, problems of the long cycling time, the unsatisfactory COP, and the large system size all need studies in depth ${ }^{[2]}$. The efficient utilization of the solar energy is the basis of the performance of the system. An optimum system must combine the cooling cycle with the solar movement effectively. As the sun moves in the sky, the solar radiation intensity changes all the time. It is hoped that the solar collector is able to harvest effectively the solar energy in diurnal. Though many approaches were proposed for the purpose of solar collecting, the cylindrical collector of glass tube, combining with a parabolic trough, is basically consistent with those requirements and then obtained popular application ${ }^{[3,4]}$. In a system of adsorption cooling, the bed and the solar collector are the main parts. How to combine the bed and the collector effectively is very important and it will affect the performance of the system strongly ${ }^{[5,6]}$. Choudhury et al. summarized two ways to capture the solar energy ${ }^{[7]}$. One way is to put directly the adsorbent bed into the solar collector, the other way is to use a solar collector to heat the fluid firstly, and then to heat the bed by the fluid.

The performance of the bed depends strongly on the characteristic of the heat and mass transfer. To improve the cooling performance, the bed must transfer effectively the solar heat to the adsorbent material inside, so that the desorption of the adsorbent is able to conduct. On the other hand, the bed must be able to dissipate the heat generation during the adsorption process as soon as possible to promote the adsorption to be perfect. Different bed results in different cooling performance of the system. Upon analyzing the mechanism of the adsorption refrigeration for the air conditioner in automobile, Suzuki emphasized the great importance of the bed design ${ }^{[8]}$. Till today, there have been a large number of study reports on the adsorption cooling system. The studies were mainly concentrated on three aspects: to improve the characteristics of the adsorbent 
itself $^{[9,10]}$, to develop composite adsorbents of good heat transfer ${ }^{[11]}$, and to optimize the structure of the bed ${ }^{[12]}$. Chang et al pointed out that the adsorption bed of thinner layer material is more satisfactory in terms of mass transfer [13]. Sun et al established a one-dimensional model to simulate the coupled heat and mass transfer in the adsorber that was heated by the eternal fluid ${ }^{[14]}$. Zhang et al present a theoretical study on the heat transfer subjected to an unsteady boundary condition to obtain the coupling temperature distribution in the adsorbent bed ${ }^{[15]}$.

In the current study, we present a theoretical heat-transfer model of the adsorption bed with the unsteady boundary condition of solar radiation. With application of CFD software, the temperature distribution of the adsorbent in the bed under the solar insolation will be investigated. Meanwhile, the effect of the internal cooling condition and the tube size on the heat transfer will also be detected. Due to the characteristic of heat transfer of the bed is closely connected to the performance of the adsorption cooling cycle, the current study will lay a basis for the next study of adsorption and desorption, and supply helpful suggestions to the design of the bed.

\section{Physical and Mathematical Model}

\subsection{Structure of the Adsorption Bed}

In addition to the function of heat transfer, the adsorption bed is also responsible for the mass transfer between the adsorbent material and the refrigerant. This suggests that some channels for the mass transfer must be taken into account in the bed design. Conventionally, the flat plate adsorber was used mostly ${ }^{[16]}$. With great heat losses the flat plate adsorber reaches a temperature usually less than $80^{\circ} \mathrm{C}$. In contrast, the evacuated tube bed shows much better characteristics, not only for the good effect of the evacuated insulation layer, but also for the excellent pressure-bearing capacity ${ }^{[17,18]}$. Such kind of tube collector has been widely applied in the solar engineering today. Bansal et al also studied the performance of some adsorption systems that used the vacuum tube as the bed ${ }^{[19]}$. Although such kind of bed possessed advantages mentioned above, there still remained problems to be solved, such as the low thermal utilization efficiency because of the heating medium, and the difficulty of the heat dissipation in the adsorption process. In the current study, the adsorption bed is reformed from the basic structure of the vacuum tube collector. The section diagram of the tube bed is shown in Fig.1. It is composed of the outer glass tube, the inner solar-absorbing alloy tube, and the copper tube as the cooling channel. The adsorption material is put into the annular cavity that is formed by the alloy tube and the cooling channel. The vacuum layer functions as the thermal insulation layer.

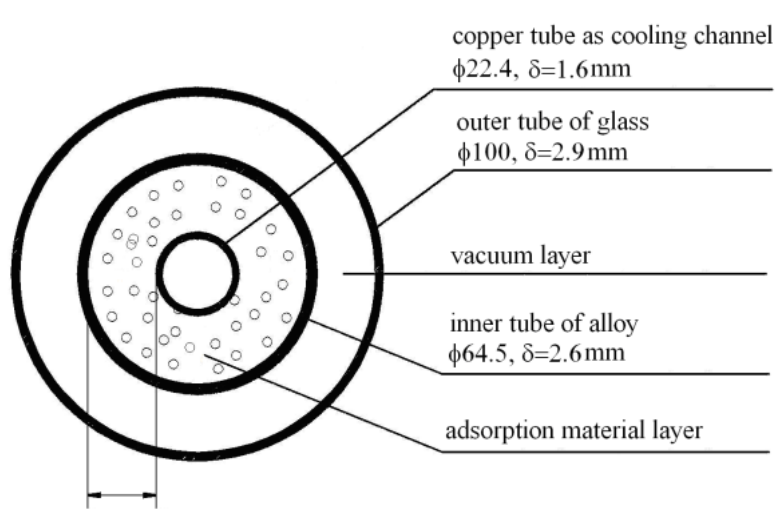

$18.4 \mathrm{~mm}$

Figure 1. Cross-sectional schematic of the evacuated tube bed

\subsection{Assumptions to the Numerical Model}

For the bed structure shown in Fig.1, a two-dimensional mathematical model is established. In the model the solar heat flux onto the bed is invariable along the tube axis but variable around the circumference of the tube. The solar radiation, which changes with the time all the day, will cause the transient heat transfer in the bed. The numerical domain includes the adsorbent region and the tube banks. To facilitate the simulation, some assumptions were made as the following.

a) The heat loss of the evacuated bed is little enough and can be neglected.

b) No thermal convection and radiation exists in the bed, and the pressure inside is homogeneous.

c) The bed is deployed in such a way that the sunlight irradiates the tube surface to the normal all the time, and the sunlight is assumed to be parallel precisely.

d) Similar to the assumption in ${ }^{[20]}$, the adsorbent is closely contact with tube wall and no thermal contact resistance need to consider.

\subsection{The Solar Heat Flux onto the Bed}

With the movement of the sun in the sky, the solar radiation intensity observed on the ground is variable. The solar heat flux is a function both of the time and the latitude of the observing spot. The variation of the solar flux can described as

$$
q_{s}(\tau)=q_{m} \cdot \sin (\omega \tau)
$$

Where $q_{m}$ denotes the maximum solar heat flux in a day, which occurs at the noon of the local time. $\tau$ is the time calculating from the sunrise in the morning, and the angular speed of the solar movement is $\omega=\pi / 12$. In the current study the solar radiation will be determined by the equinox day, which means the sun rises from the due east and sets to the due west. The diurnal time is precisely 12 hours, as shown in Fig. 2. 


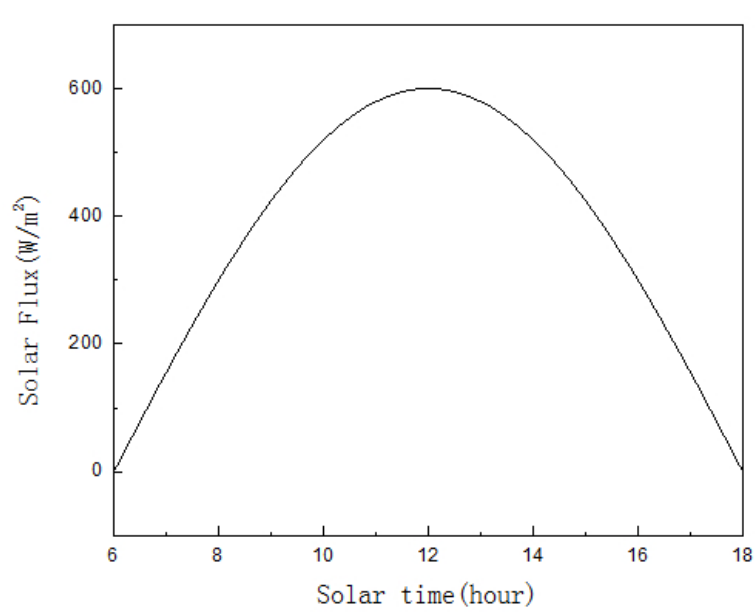

Figure 2. Variation of the solar radiation in the equinox day

With the consideration of the uniform sunshine, half of the tube will be irradiated all the time, and the solar heat flux is variable along the circumference of the tube. To describe mathematically the numerical model of the tube bed, a polar coordinate system is adopted as shown in Fig.3. In the figure $r$ represents the due east where the sun rises and $\varphi$ is the circumferential direction. The $\omega \tau$ denotes the swept angle of the sunlight. The solar heat flux that reached to the tube surface is described as

$$
\begin{cases}q(\varphi, \tau)=q_{s}(\tau) \cdot \cos (\varphi-\omega \tau), & \omega \tau-\frac{\pi}{2} \leq \varphi \leq \omega \tau+\frac{\pi}{2} \\ q(\varphi, \tau)=0, & \omega \tau+\frac{\pi}{2}<\varphi<\omega \tau+\frac{3 \pi}{2}\end{cases}
$$

The point $\mathrm{A}, \mathrm{B}$, and $\mathrm{C}$ in Fig. 3 are three monitored points. They are all located at the midway of the adsorbent annulus, with A to the solar-facing top, $\mathrm{C}$ to the shading bottom, and $\mathrm{B}$ to the west. The $\mathrm{m}-\mathrm{n}$ line is the symmetrical plane on the $\mathrm{r}$ axis, on which the local temperature distribution will be discussed in the following paragraph.

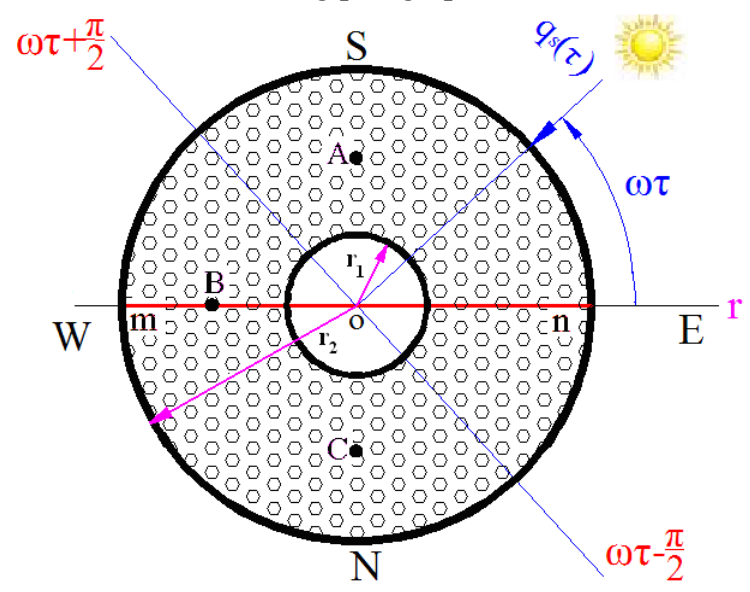

Figure 3. The solar movement in relation to the bed

\subsection{Governing Energy Equation}

Corresponding to the coordination in Fig.3, the mathematical description of the conduction problem is as

$$
\begin{gathered}
\frac{1}{\alpha} \frac{\partial t}{\partial \tau}=\frac{\partial^{2} t}{\partial r^{2}}+\frac{1}{r} \frac{\partial t}{\partial r}+\frac{1}{r^{2}} \frac{\partial^{2} t}{\partial \varphi^{2}} \\
\tau=0,\left.t(r, \varphi, \tau)\right|_{\tau=0}=T_{0}
\end{gathered}
$$

$r=r_{1}, \lambda\left(\frac{\partial t}{\partial r}\right)_{w}=h\left(t_{w}-t_{f}\right)$ for the convection condition of cooling

or $\left.t\left(r_{1}, \varphi\right)\right|_{w}=t_{w}$ for the uniform wall temperature of cooling

$$
r=r_{2}, \lambda\left(\frac{\partial t}{\partial r}\right)_{w}=q(\varphi, \tau)
$$

where $\alpha$ is the thermal diffusivity of the adsorbent material, $\lambda$ is the thermal conductivity, and $h$ is the convective heat transfer coefficient between the channel surface and the cooling fluid.

\subsection{Validation of the Mathematical and Numerical Models}

Usually the accuracy of the numerical result changes with the fineness of the grid in the domain, therefore it is necessary to perform a test of the grid independence to guarantee the reliability and accuracy of the numerical simulation. The temperature change of point A, B, C shown in Fig. 3 with the grid number has been monitored during the test, and the result is presented in Table 1 and Fig.4. One can see that as the grid number changes from 10,200 to 114,582 , the temperature changes up and down around some mean value. The maximum variation of the temperature is $1.6 \mathrm{~K}$ (for point $\mathrm{A}$ ) and the minimum is only $0.4 \mathrm{~K}$ (for point $\mathrm{C}$ ). Thus we did not think that the grid number in between the range above affected the numerical very much, and the grid number of 28956 was adopted in the afterwards simulation.

Table 1. Convergence temperature of A, B, and C for different grid numbers $(\mathrm{K})$

\begin{tabular}{|c|c|c|c|}
\hline Grid number & Point A & Point B & Point C \\
\hline 10200 & 443.7 & 390.5 & 365.6 \\
28956 & 444.4 & 391.1 & 365.9 \\
51376 & 442.8 & 389.9 & 365.6 \\
114582 & 444.2 & 391.2 & 366.0 \\
\hline
\end{tabular}

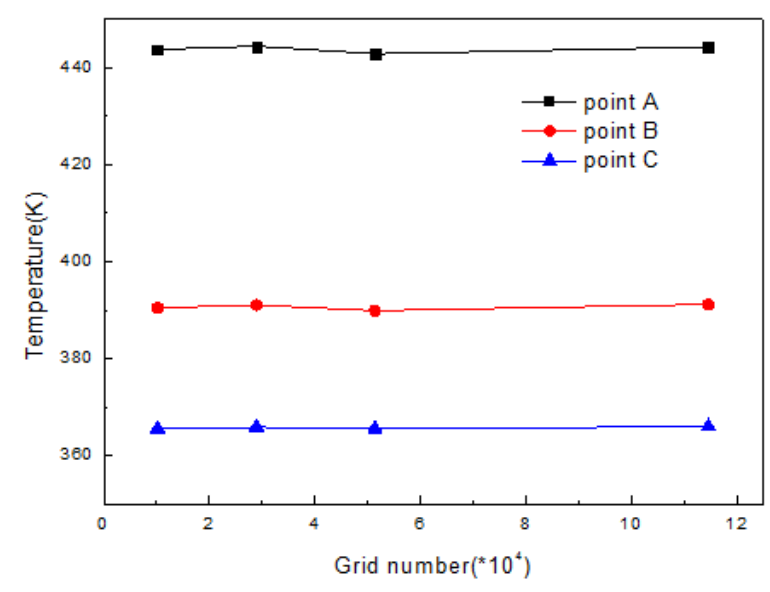

Figure 4. Result of grid independence test for point A, B, and C 


\section{Numerical Results of Temperature Field of the Bed}

Based on the mathematical model, the 2-D heat transfer in the bed has been studied with the FLUENT software. In the simulation the maximum solar heat flux in Eq.(1) is set as $q_{m}=600 \mathrm{~W} / \mathrm{m}^{2}$, which is basically consistent to the solar radiation in the spring of Beijing. The adsorption material is assumed as silica gel. The average physical property is taken as the bulk density $\rho=790 \mathrm{~kg} / \mathrm{m}^{3}$, the specific heat $\mathrm{c}_{\mathrm{p}}=920 \mathrm{~J} /$ $(\mathrm{kg} \cdot \mathrm{K})$, and the thermal conductivity $\mathrm{k}=0.175 \mathrm{~W} /(\mathrm{m} \cdot \mathrm{K})$. The initial temperature of the bed is set as $\mathrm{T}_{0}=300 \mathrm{~K}$.

Three cooling boundary conditions have been investigated into the effect on the heat transfer of the bed. The difference of the boundary condition is indicated by the cooling mode of the internal cooling channel in Fig.1. As is known the heat transfer coefficient is affected by many factors in convection. It depends not only on the flow velocity of the fluid, but also on the physical properties of the fluid, on the shape of the tube, and on the flow-driving mode. At the same flow velocity, the heat transfer coefficient of the air and the water can be quite different just because of their different physical properties. In the current study the cooling condition of the internal channel is supposed to be the uniform wall temperature or the convection of air/water with the parameters as following,

a) natural air convection, $t_{\mathrm{f}}=300 \mathrm{~K}, \mathrm{~h}=6 \mathrm{~W} /\left(\mathrm{m}^{2} \cdot \mathrm{K}\right)$, in consideration of the heat transfer coefficient of natural air convection is ranged $3 \sim 10 \mathrm{~W} /\left(\mathrm{m}^{2} \cdot \mathrm{K}\right)$, by the

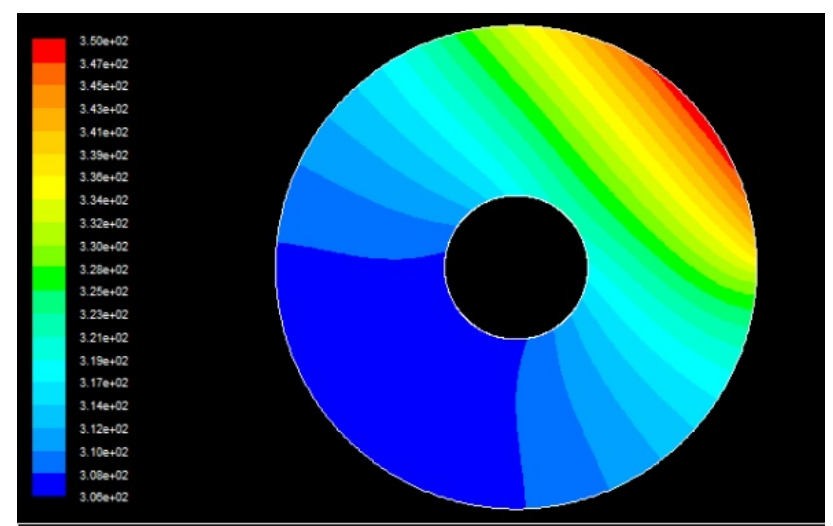

(a) $t=2 h$

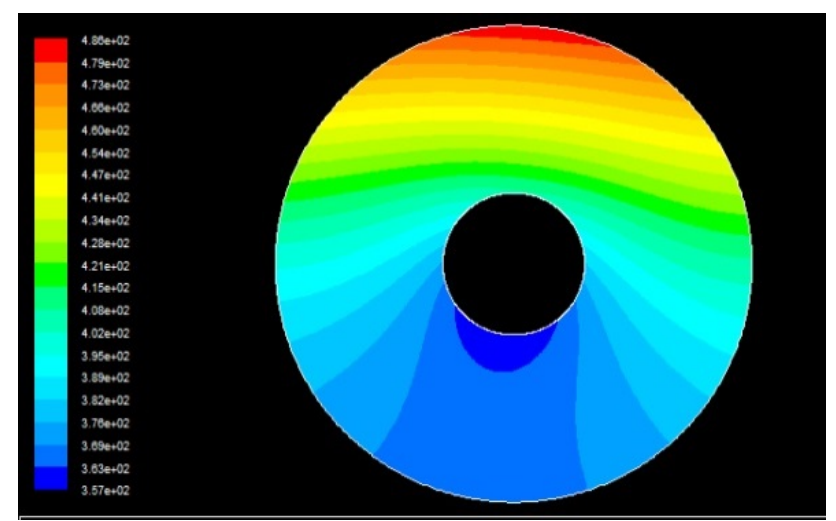

(c) $t=6 h$ handbook of heat transfer.

b) uniform wall temperature of the cooling channel, $t_{w}=$ $300 \mathrm{~K}$.

c) natural water convection, $\mathrm{t}_{\mathrm{f}}=300 \mathrm{~K}, \mathrm{~h}=500 \mathrm{~W} /\left(\mathrm{m}^{2} \cdot \mathrm{K}\right)$, in consideration of the heat transfer coefficient of natural water convection is ranged 200 1000 $\mathrm{W} /\left(\mathrm{m}^{2} \cdot \mathrm{K}\right)$, by the handbook of heat transfer.

Firstly, the temperature evolution of the bed at the boundary condition (a) was simulated. During the solar heating time in a day, which corresponds to exact 12 hours for the supposed equinox day, the internal temperature field of the bed changes as the pattern series in Fig.5.

As seen from Fig.5 the hot region moves with the sun from the right side to the left gradually. Meanwhile, the hot region expands and the cool region diminishes. The cool region is opposite to the hot side, and the coolest spot locates near the cooling channel bank. The temperature of the hot region and the cool region distributes respectively to some symmetrical plane. Before $\mathrm{t}=4$ hours the two regions almost share the same symmetrical plane. After that time the hot region moves forth faster and the symmetrical plane does not coincident any more. Though the symmetrical plane is related to the solar direction, they are not exactly the same. Because of the poor thermal diffusivity of the porous material, there must be a time delay for the temperature field to catch up with the solar movement. This time delay depends on the physical properties of the material and also on the configuration of the bed.

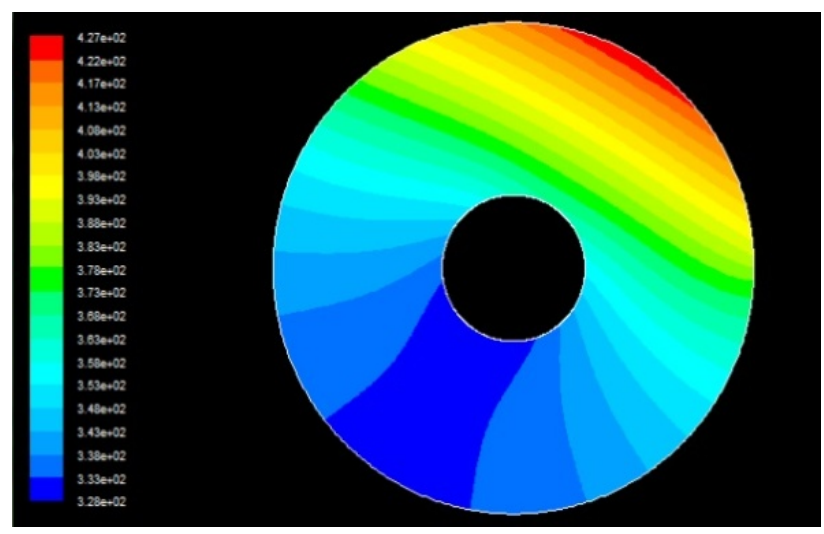

(b) $t=4 h$

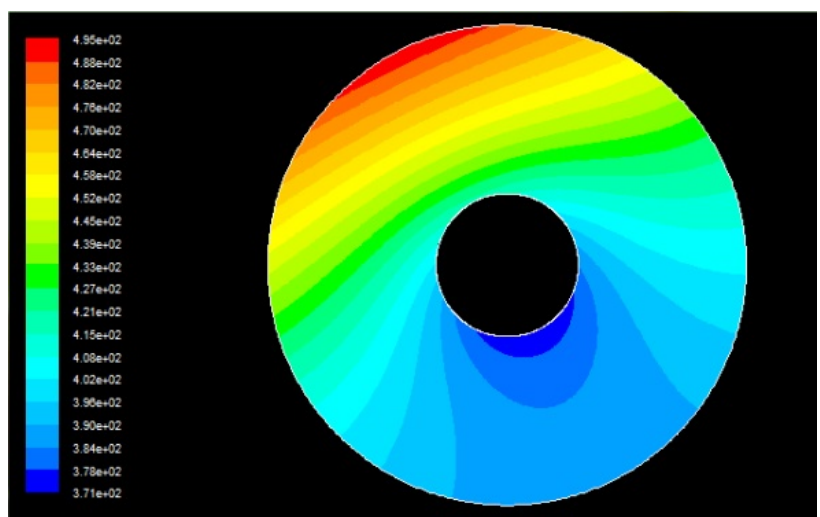

(d) $t=8 h$ 


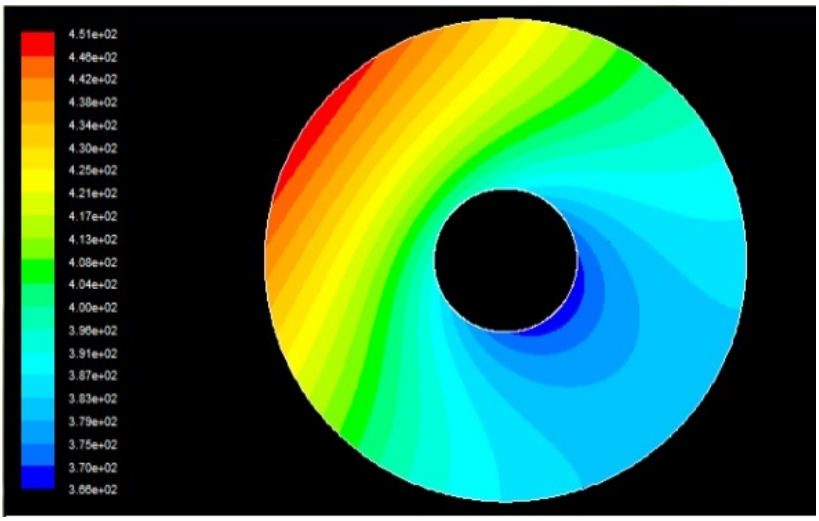

(e) $t=10 h$

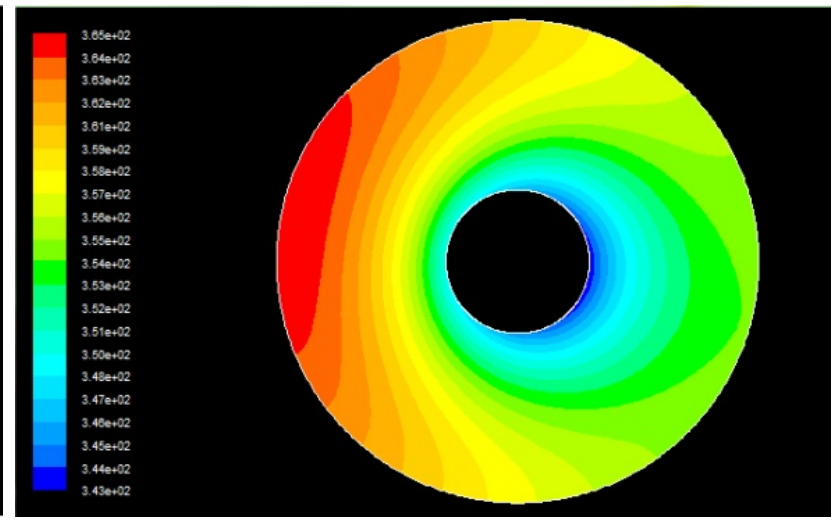

(f) $t=12 h$

Figure 5. Temperature evolution of the bed with the solar heating time
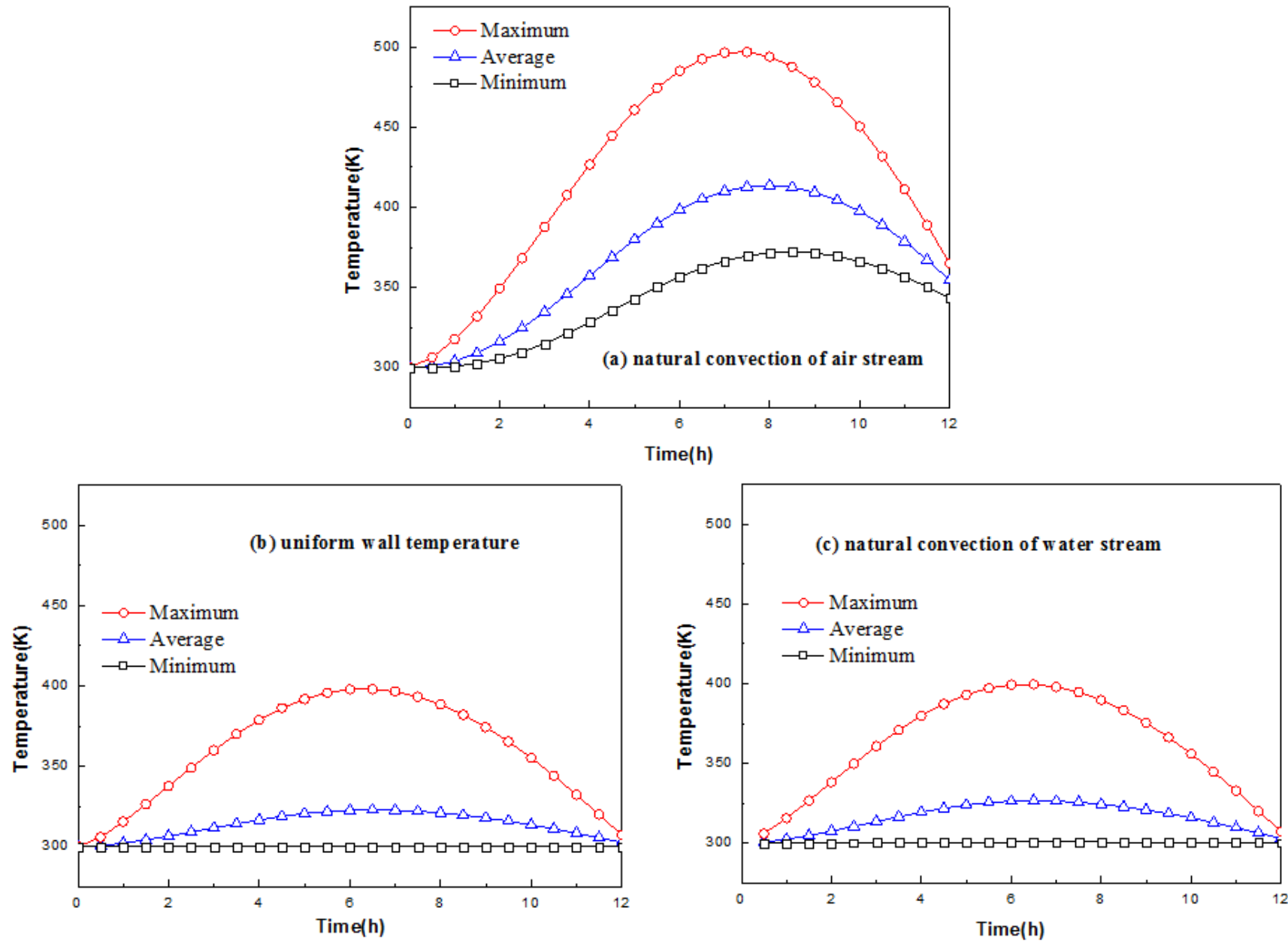

Figure 6. Temperature change of the bed in general

\section{Effect of Cooling Boundary Condition on Bed Temperature}

The effect of the boundary condition of the cooling channel has been identified on the temperature of the bed. The boundary condition involves the uniform wall temperature, the natural convection of air stream, and the natural convection of water stream. The change of the temperature filed is indicated by the maximum, the minimum, and the average temperature at different time, as presented in Fig.6. From the results it is found that the time to the summit temperature of the bed for the natural air convection is later than the time for the other two boundary conditions. Correspondingly, the maximum temperature for the former is higher than for the others, too. The maximum temperature reaches almost $500 \mathrm{~K}$ under the natural air convection condition, while it is only $400 \mathrm{~K}$ for the uniform wall temperature condition. After 12 hours the temperature of the bed at the condition of the natural air convection falls down to around $350 \mathrm{~K}$, but it is down to around $300 \mathrm{~K}$ for the 
other two cases.

Different from the situation of the uniform temperature or the water cooling condition, for the air cooling case the maximum temperature of the bed does not occur at the noon time exactly. There is about one and a half hour of time delay for the maximum temperature in comparison to the maximum solar radiation at the noon. This phenomenon does not occur for the other two cases. The continual temperature rising means the accumulation of the heat in the bed. This can be interpreted by the energy balance between the imported and the dissipated energy. As the bed is cooled by the natural air stream, the convective heat transfer in the cooling tunnel is weak and not matches to the intensive solar radiation around the noon time. As a result, the thermal energy is accumulated inside and causes the temperature to increase continually. In contrast, for the case of the water convection or the uniform temperature the heat transfer of the cooling tunnel is stronger. A balance of the imported and the dissipated heat is basically kept, thus the solar radiation and the bed temperature reaches the maximum almost the same time. It is clear that the cooling ability of the uniform temperature boundary or the convection of water stream boundary is far stronger than the natural convection of air. Especially, the uniform temperature boundary can be seen as the equivalent case of convection with an infinite heat transfer coefficient of the fluid with the same temperature.
As mentioned above for Fig. 3, A, B, and $\mathrm{C}$ point is located at special spot of the bed cross section. Their temperature changes represent the situation of the whole bed to some extent. The monitored result for the three points is shown in Fig.7.

It is clear that the curve of the temperature variation of the points is different one another for any cooling condition. It seems that the boundary condition affects the top and the bottom of the bed in a different way, in that the temperature of A point ups and downs more seriously than the other two points. On the other hand, under the cooling condition of natural air stream, all the three curves of A, B, and C changes more drastically. In contrast, for the cases of uniform wall temperature or the water convection condition, the curve of $\mathrm{C}$ point tends to be flat, which means that the solar radiation does not affect the local temperature very much. Another interesting phenomenon is the crossing of the curve of $A$ and $\mathrm{B}$ at $\tau=9.3$ hour in all the plots. Beyond the crossing point the temperature of $\mathrm{B}$ becomes higher than that of $\mathrm{A}$, which is the result of the solar irradiation onto the west part of the bed in the afternoon. The time delay is also a feature to note. Obviously, the summit time of the temperature is of great difference one another. For point $\mathrm{A}$ and $\mathrm{C}$ the time delay is as much as 3 hours, with the bottom $\mathrm{C}$ always the latest to the summit. In contrast, the time delay between point $\mathrm{B}$ and $\mathrm{C}$ is less than one hour.
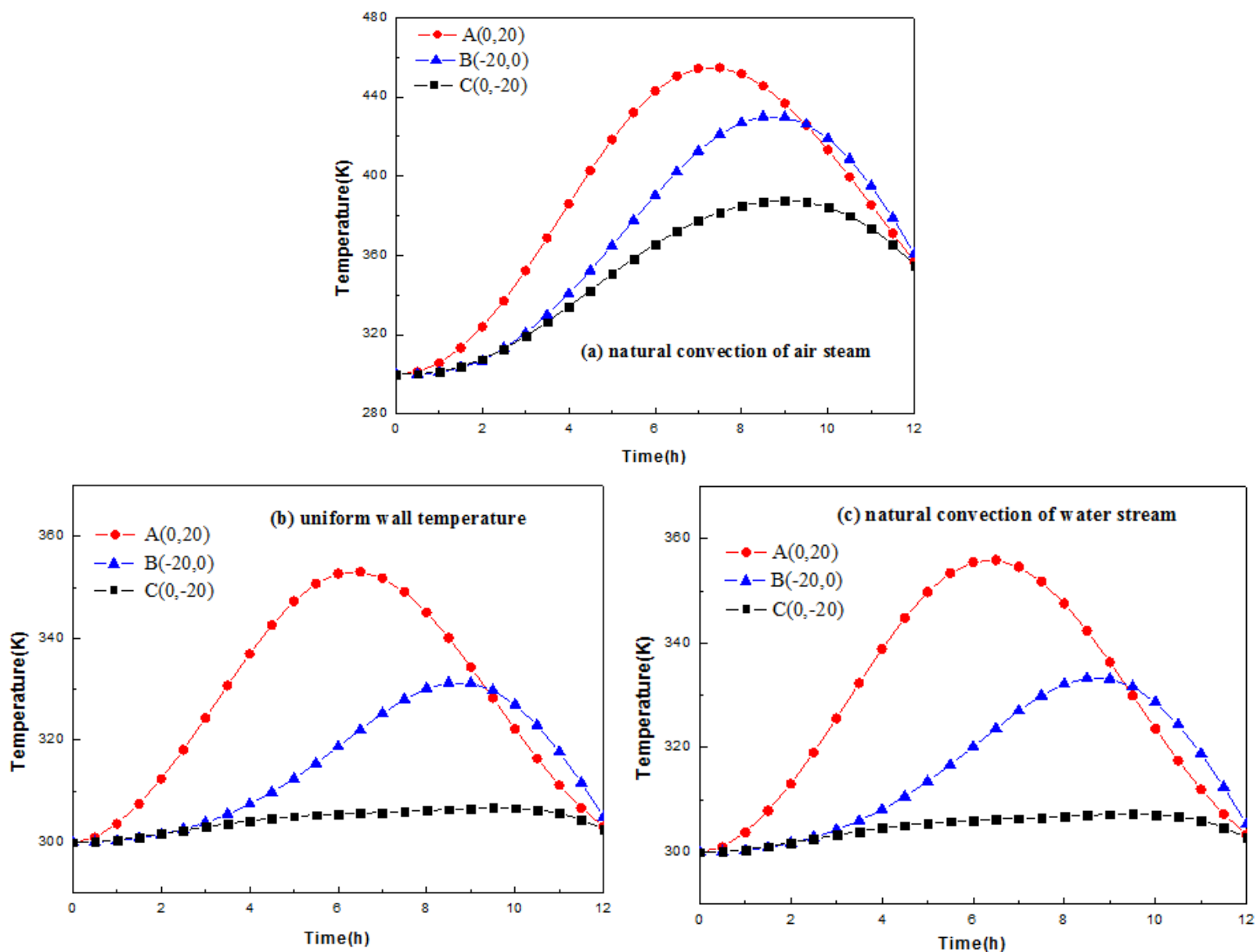

Figure 7. Temperature change of the monitored $\mathrm{A}, \mathrm{B}$, and $\mathrm{C}$ points 


\section{Effect of the Tube Size on the Temperature Change}

The variation of the temperature in the evacuated tube bed is a comprehensive result that is from the influence of solar heating, the cooling condition, and the configuration of the bed itself. Due to the bed form is an annular cavity between the solar heating alloy tube and the cooling tunnel tube, the size of the tube will definitely impacts the performance of the bed. In this part we discuss the effect of the radius of the outer and the inner tube on the bed temperature. Fig.8 (a) shows the effect of the solar heating alloy tube on the maximum temperature of the bed, and Fig.8 (b) is for the effect of the cooling tube. Both Fig.8 (a) and (b) are all obtained under the natural convection of air condition. As seen in Fig.8 (a), for a given radius $r_{1}$ of the cooling tube, the temperature of the bed increases with the radius $r_{2}$ of the alloy tube. The difference of the maximum temperature for $\mathrm{r}_{2}=20 \mathrm{~mm}$ and $50 \mathrm{~mm}$ reaches $130 \mathrm{~K}$ at most. Correspondingly, the time to the summit temperature delays as the $r_{2}$ increase. On the other hand, if the size of the alloy tube is kept invariable as shown in Fig.8 (b), the smaller the cooling tube, the higher the bed temperature. In fact, the result in Fig. 8 (a) and (b) represents the similar effect of the adsorbent layer. Increasing the $r_{2}$ or decreasing the $r_{1}$ both means that the bed thickness enlarges. A thick bed obstructs the heat to dissipate to the cooling fluid and results in the temperature to rise, especially for the porous material of poor conductivity. A thinner bed layer is always favorable in the adsorption heat pump.

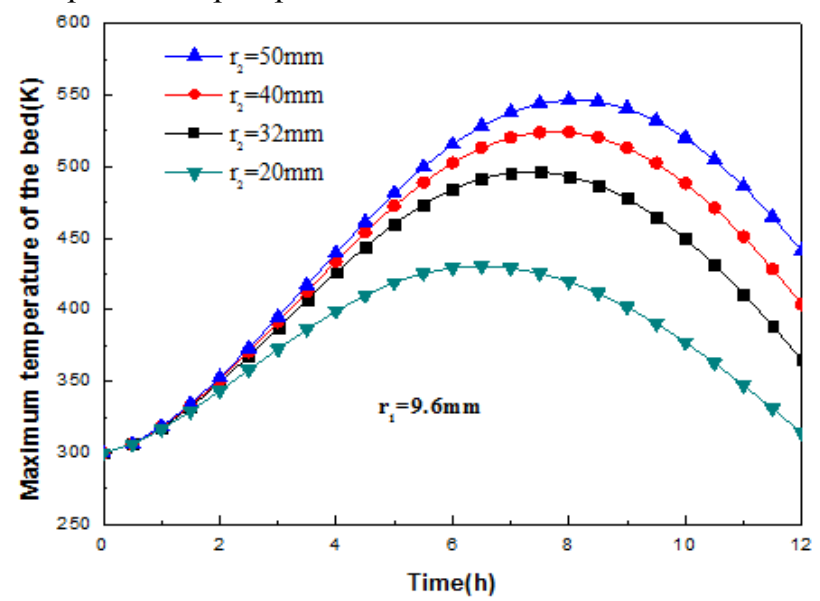

(a) effect of the alloy tube radius $r_{2}$

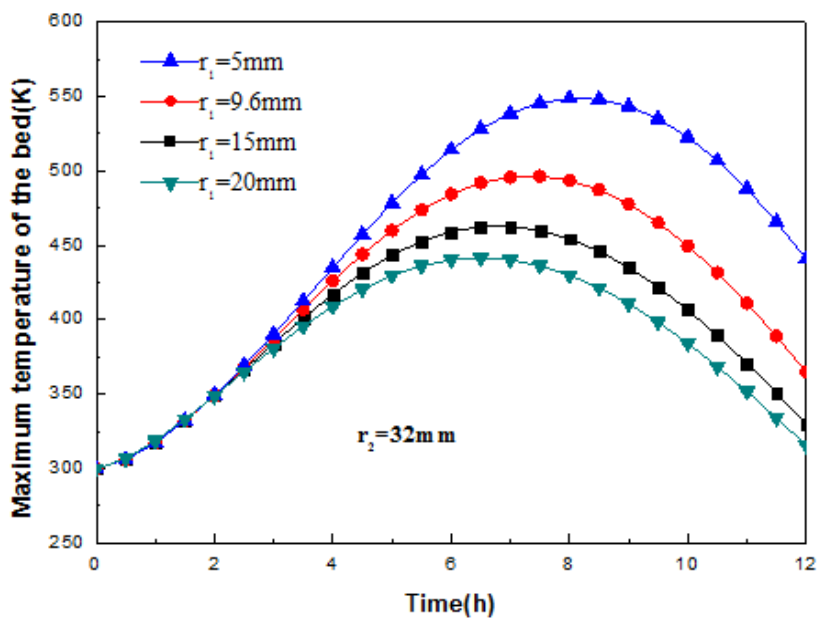

(b) effect of the cooling tube radius $r_{1}$

Figure 8. Bed maximum temperature varies with the time for different tube sizes

In comparison, the effect of the alloy tube size is considered to be more important to the bed temperature. If we check the relationship of the tube radius $r_{2}$ and the bed temperature for the cases in Fig.8 (a), some curves are obtained as shown in Fig.9. Although the maximum temperature of the bed increases over $110 \mathrm{~K}$ as $r_{2}$ changes from $20 \mathrm{~mm}$ to $50 \mathrm{~mm}$, the average temperature increases less than $70 \mathrm{~K}$, and the minimum temperature increment is even less. There is really a contradiction between the tube size and the heat transfer. In the view of the performance of the system, we need more adsorbent material to put into the bed. But the large bed has the difficulty of heat transfer, and quite often need to be enhanced.

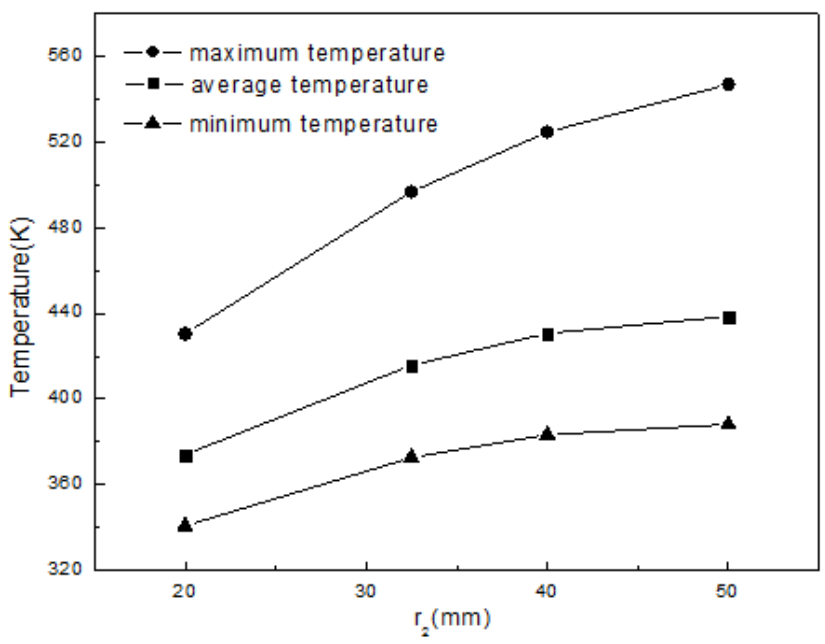

Figure 9. Effect of the alloy tube radius on the whole bed temperature 
Under the natural air convection cooling condition, the local temperature distribution along the m-n symmetrical line, as shown in Fig.3, is drawn up from the simulation result. At the solar-heating time $\tau=6$ hours, which corresponds to the exact noon time, the local temperature along the m-n line is as shown in Fig.10. Note that the positive direction of the abscissa is the east direction. With the sunrise from the east and the solar heating in the morning, the right part of the temperature profile is clearly higher than the left part. To the edge of the bed there is approximately a temperature difference of $10 \mathrm{~K}$. Nevertheless, a great gradient of temperature occurs in the radial direction. The both parts of the profile shows a steep dropping of the temperature, which tell us that the heat transfer from the outer layer of the bed to the inner cooling channel is tough, and some type of heat transfer enhancement is necessary in the practice.

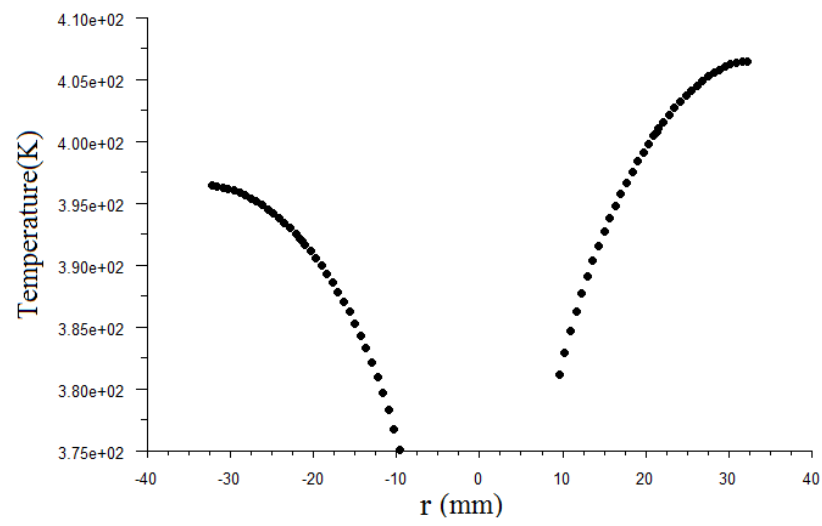

Figure 10. Local temperature distribution along the $m-n$ symmetrical line of the bed, for the condition of natural air convection, time $=6$ hour

\section{Conclusions}

Towards the application in the solar driven adsorption cooling system, an evacuated tube bed under the solar insolation has been numerically simulated to investigate the temperature evolution with the heating time. Both the effect of the cooling boundary condition and of the tube size on the temperature field has been identified. The numerical results have revealed that the cooling boundary condition impact the thermal performance of the bed seriously. In general, the boundary condition of uniform wall temperature or water convection cools the bed much stronger than the condition of the natural air convection, and the temperature summit is basically consistent with the solar movement. For the condition of natural convection of air stream, due to the weak heat transfer the bed can reaches a higher temperature summit, in addition to a longer time delay with relation to the solar maximum radiation. Under the natural air cooling condition the time delay of the bed temperature with the maximum solar radiation is about two hours later, while for the other two cases the time delay is less than half hour. The evolving pattern of the bed temperature can be well interpreted by the difference of the heat transfer determined by the boundary condition. For any case, there exists a great temperature difference between the solar facing side and the solar shading side. The temperature difference between them can be as great as $70 \mathrm{~K}$. Similarly, there is also a great temperature gradient along the radial direction of the bed. As the diameter of the solar-absorbing tube increases or the cooling channel tube diminishes, the adsorbent domain enlarges and this results in greater temperature gradient.

\section{NOMENCLATURE}

$\begin{array}{cll}\mathrm{c}_{\mathrm{P}} & {[\mathrm{J} /(\mathrm{kg} \cdot \mathrm{K})]} & \text { specific heat } \\ \mathrm{h} & {\left[\mathrm{W} /\left(\mathrm{m}^{2} \cdot \mathrm{K}\right)\right]} & \begin{array}{l}\text { convective heat transfer coefficient } \\ \mathrm{q}\end{array} \\ \mathrm{q}_{\mathrm{m}} & {\left[\mathrm{W} / \mathrm{m}^{2}\right]} & \text { heat flux } \\ \mathrm{q}_{\mathrm{s}} & {\left[\mathrm{W} / \mathrm{m}^{2}\right]} & \text { maximum solar radiation intensity } \\ \mathrm{r} & {[\mathrm{mm}]} & \begin{array}{l}\text { solar radiation intensity } \\ \text { radial coordination }\end{array} \\ \mathrm{r}_{1} & {[\mathrm{~mm}]} & \text { radius of the cooling tube } \\ \mathrm{r}_{2} & {[\mathrm{~mm}]} & \text { radius of the solar-absorbing alloy tube } \\ \mathrm{t} & {[\mathrm{K}]} & \text { temperature } \\ \mathrm{t}_{\mathrm{f}} & {[\mathrm{K}]} & \text { temperature of the cooling fluid } \\ \mathrm{t}_{\mathrm{w}} & {[\mathrm{K}]} & \text { temperature of the tube wall } \\ \mathrm{T}_{0} & {[\mathrm{~K}]} & \text { initial temperature of the bed } \\ & & \\ \mathrm{Greek} & \mathrm{symbol} & \\ \alpha & {[\mathrm{m} / \mathrm{s}]} & \text { thermal diffusivity } \\ \varphi & {\left[{ }^{\circ}\right]} & \text { angular coordination } \\ \lambda & {[\mathrm{W} /(\mathrm{m} \cdot \mathrm{K})]} & \text { thermal conductivity } \\ \rho & {\left[\mathrm{kg} / \mathrm{m}^{3}\right]} & \text { material density } \\ \tau & {[\mathrm{h}]} & \text { time } \\ \omega & {[\mathrm{rad} / \mathrm{h}]} & \text { angular speed of the solar movement }\end{array}$

\section{Acknowledgements}

This research work is sponsored by the National Natural Science Foundation of China (Grant No. 51276005).

\section{REFERENCES}

[1] R.Z. Wang, Adsorption refrigeration research in Shanghai Jiao Tong University, Renewable and Sustainable Energy Reviews, vol.5, 2001, pp. 1-37

[2] C.H. Li, R.Z. Wang, Y.J. Dai, Simulation and economic analysis of a solar-powered adsorption refrigerator using an evacuated tube for thermal insulation. Renewable Energy, vol.28, 2003, pp. 249-269

[3] O. S. Headley, A. F. Kohdinala, I. A. Doom, Charcoal-methanol adsorption refrigerator powered by a compound parabolic concentrating solar collector, Solar Energy, vol.53, 1994, pp. 191-197

[4] A. A. Hachicha, I. Rodríguez, R. Capdevila,, A. Oliva, Heat transfer analysis and numerical simulation of a parabolic trough solar collector, Applied Energy, vol.111, 2013, pp. 581-592 
[5] D.C. Wang, Y.H. Li, D. Li, Y.Z. Xia, J.P. Zhang, A review on adsorption refrigeration technology and adsorption deterioration in physical adsorption systems. Renewable and Sustainable Energy Reviews, vol.14, 2010, pp. 344-353

[6] K. Sumathy, Z. F. Li, Experiments with solar-powered adsorption ice-maker. Renewable Energy, vol.16, 1999, pp. 704-707

[7] B. Choudhury, B.B. Saha, P. K. Chatterjee, J. P. Sarkar, An overview of developments in adsorption refrigeration systems towards a sustainable way of cooling. Applied Energy, vol.104, 2013, pp. 554-567

[8] M. Suzuki, Application of adsorption cooling system to automobiles. Heat Recovery Systems \& CHP, vol.13, 1993, pp. $335-340$

[9] W.S. Loh, I.I. El-Sharkawy, K.C. Ng, B.B. Saha, Adsorption cooling cycles for alternative adsorbent/ adsorbate pairs working at partial vacuum and pressurized conditions. Applied Thermal Engineering, vol.29, 2009, pp. 793-798

[10] L.W. Wang, R.Z. Wang, R.G. Oliveira, A review on adsorption working pairs for refrigeration. Renewable and Sustainable Energy Reviews, vol.13, 2009, pp. 518-534

[11] L.W. Wang, S.J. Metcalf, R.E. Critoph, R. Thorpe, Z. T. Telto, Development of thermal conductive consolidated activated carbon for adsorption refrigeration. Carbon, vol.50, 2012, pp. $977-986$

[12] X.Q. Zhai, R.Z. Wang, Experimental investigation and performance analysis on a solar adsorption cooling system with/without heat storage. Applied Energy, vol.87, 2010, pp. 824-835

[13] K.S. Chang, M.T. Chen, T.W. Chung, Effects of the thickness and particle size of silica gel on the heat and mass transfer performance of a silica gel-coated bed for air-conditioning adsorption systems, Applied Thermal Engineering, vol.25, 2005, pp. 2330-2340

[14] L. M. Sun, N. Ben Amar and F. Meunier, Numerical study on coupled heat and mass transfers in an adsorber with external fluid heating. Heat Recovery Systems \& $C H P$, Vol. 15. No. 1, pp. 19-29. 1995

[15] X.J. Zhang, H.X. Liu, R.Z. Wang, F. Shi, Numerical simulation of heat transfer in regenerator of solid adsorption refrigeration system, Renewable Energy, vol.26, 2002, pp.599-610

[16] M. Pons, J.J. Guilleminot, Design of an experimental solar-powered, solid-adsorption ice maker, Transactions of the ASME, Journal of Solar Engineering, vol.108, 1986, pp. $332-337$

[17] A. P. F. Leite, M. Daguenet, Performance of a new solid adsorption ice maker with solar energy regeneration. Energy Conversion and Management, vol.41, 2000, pp. 1625-1647

[18] C.X. Du, Z.X. Yuan, X.H. Hou, F. Xin, D.D. Gao, Y.C. Chen, Temperature evolution of evacuated tube adsorption bed heated by solar radiation, Proceedings of 15th Int. Heat Transfer Conference, IHTC15-8530, August 10-15, 2014, Kyoto, Japan

[19] N.K. Bansal, J. Blumenberg, H.J. Kavasch, T. Roettinger, Performance testing and evaluation of solid absorption solar cooling unit, Solar Energy, vol.61, 1997, pp.127-140

[20] H. Niazmand, I. Dabzadeh, Numerical simulation of heat and mass transfer in adsorbent beds with annular fins. International Journal of Refrigeration, vol.35, 2012, pp. 581-593 